\title{
Histological Study on the Obliteration Process of Ductus Arteriosus in Still Born Fetuses
}

\author{
${ }^{1}$ Meera Kugananthan*, ${ }^{2}$ Sadeesh. T, ${ }^{3}$ Hydrina D' Silva, ${ }^{4}$ Anbalagan. J, \\ ${ }^{5}$ Sudha Rao \\ 1,2,3,4,5 Department of Anatomy, Mahatma Gandhi Medical College \& Research Institute, Puducherry
}

\begin{abstract}
: 30 still born fetuses of age group (13-40weeks) were studied macroscopically and microscopically to observe the sequential changes in the obliteration process of Ductus arteriosus. The Ductus arteriosus (DA) was found to originate either from left pulmonary artery or from the bifurcation of pulmonary trunk. Significant changes in the length, outer and inner diameter of DA were observed in different gestational period. The tunics of DA showed structural changes in arrangement of muscle layers, appearance of intimal cushion, organization of elastic and collagen fibers. The proliferation and migration of muscle fibers from tunic media and formation of intimal cushion marked the process of gradual closure of DA.
\end{abstract}

Key words: Ductus Arteriosus, intimal cushion, intimal mounds, internal elastic lamina

\section{Introduction}

The Ductus Arteriosus (DA) is a vascular structure connecting proximal part of descending aorta with pulmonary trunk. The DA reduces the work load of developing lungs by shunting more than $90 \%$ of right ventricular output blood to the aorta bypassing the fetal pulmonary circulation. The functional closure of DA occurs immediately after birth mediated through bradykinin, a substance released from the lungs during initial inflation [1,2]; a fall in prostaglandin level and increased blood oxygen tension due to initiation of pulmonary ventilation also favors in the functional closure of DA[3].The structural closure of DA occurs due to proliferation of intimal cushion and permanent closure occurs with complete obliteration in a period of 1-3 months after birth.

Early closure of DA results in ventricular hypertrophy and congestive heart failure. A prolonged patency of DA results in left to right shunt with cardiopulmonary distress [4]. The patency of DA in utero is maintained by low oxygen tension and vasodilators like nitric oxide, adenosine and prostaglandins [5]. The incidence of patent DA occurs in 8 in 10,000 live births. Environmental factors, rubella/viral infections and genetic predisposition play a major role in the occurrence of Patent Ductus Arteriosus (PDA)[3,4].

DA is derived from the left sixth aortic arch with contribution of migratory neural crest cells[6]. The size, shape and site of origin of DA show variations. A giant DA is represented when the external diameter exceeds $1.4 \mathrm{~cm}$ and presence of sensory and motor innervations have been reported[7,8].The DA is classified as a muscular artery and the muscular phenotype compared to the surrounding elastic arteries is the main reason for rapid constriction after birth[4]. The presence of mucoid filled spaces and fragmented elastic lamina have been observed in the walls of DA[9,10]. The appearance of intimal cushions plays a significant role in the obliteration of DA[11].

The present study is undertaken to observe the process of structural closure of DA in still born fetus of age group 17-40 weeks in south Indian population based on the histomorphometric features.

\section{Materials and methods}

The study was approved by Institutional Human Ethical Committee. 30 (19 male, 11 female)aborted dead born fetuses of age group 13-40 weeks were collected from the OBGY Department of MGMCRI and from other medical institutions in and around Pondicherry after obtaining due consent from the parents. The CR length was measured and the heart was removed along with great vessels and preserved in formalin. The site of origin of DA from the pulmonary trunk/artery, the length and patency of the DA were recorded. The fetuses were grouped age wise: Group A (13-20weeks), Group B (21-30weeks) and Group C (31-40weeks)

The DA from the pulmonary trunk to aorta was removed and processed for routine histological study. Six microns cut sections were stained with H\&E, Van Gieson for elastic fibers and Masson's Trichrome for collagen and muscle fibers. The diameter and thickness of tunics was measured using ocular meter.

The data's were analyzed with Karl Pearson correlation test. 


\section{Observations}

In 25 fetuses (83.33\%), the DA was found arising from the proximal part of left pulmonary artery and attached to the anterolateral part of aorta distal to the origin of left subclavian artery. In 5 fetuses $(16.66 \%)$ it was found to arise from the bifurcation of pulmonary trunk to the aorta distal to left subclavian artery (Fig.1).

The length of DA increased with gestational age. It ranged from $1.05-4.2 \mathrm{~mm}$ in group A, 3-9mm in group B and $4-10.33 \mathrm{~mm}$ in group C. The external, internal diameters and thickness of DA were found to increase in correlation with gestational age (Table.1)

Table 1. Length and diameter of $\mathrm{DA}(\mathrm{N}=30)$

\begin{tabular}{|c|c|c|c|l|l|l|c|c|}
\hline \multirow{2}{*}{$\begin{array}{c}\text { FetalAge } \\
\text { (weeks) }\end{array}$} & \multicolumn{2}{|c|}{$\begin{array}{c}\text { Length } \\
\text { mm }\end{array}$} & \multicolumn{2}{c|}{$\begin{array}{c}\text { Outer diameter } \\
\text { mm }\end{array}$} & \multicolumn{2}{c|}{$\begin{array}{c}\text { Inner diameter } \\
\text { mm }\end{array}$} & \multicolumn{2}{c|}{$\begin{array}{c}\text { Thickness of DA wall } \\
\text { mm }\end{array}$} \\
\cline { 2 - 9 } & Max & Min & Max & Min & Max & Min & Max & Min \\
\hline $13-20(6)$ & 4.2 & 1.05 & 1.9579 & 1.4146 & 1.1135 & 0.2982 & 1.018 & 0.3256 \\
\hline $21-30(12)$ & 9.00 & 3.00 & 2.5859 & 1.7728 & 1.4144 & 0.6711 & 1.320 & 0.3860 \\
\hline $31-40(12)$ & 10.33 & 4.00 & 3.2336 & 2.1647 & 2.0855 & 1.2583 & 1.800 & 0.4930 \\
\hline
\end{tabular}

In early stage of 13 weeks, the DA showed the features of muscular artery with a distinct internal elastic lamina. Absence of intimal cushions, circularly arranged muscle in tunica media, vasovasorum and nervosum in tunica adventitia were the distinctive features (Fig.2).However DA of 17 weeks showed bulging intimal cushions on one side of the wall (Fig.3) and other areas showed initial stages of proliferation and formation of sub endothelial tissue. The tunica media showed smooth muscles arranged as inner longitudinal and outer circular and tunica adventitia structured with collagen and vasovasorum and nervosum.

The DA of 21-30 weeks fetuses showed formation of well-developed intimal cushion mounds protruding towards the lumen (Fig.4).The intimal cushions were structured with prominent obliquely oriented smooth muscles migrating from tunica media and elastic fibers. The internal elastic lamina was disrupted at the site of intimal cushion and at some places duplication of elastic lamina was observed.

In DA of 31-40 weeks fetuses, intimal cushions were well formed with longitudinal oriented smooth muscle mingled with elastic and collagen fibers and proliferation of sub endothelial connective tissue. The internal elastic lamina was disrupted and in some places showed duplication and multilaminar (Fig.5). There were significant changes in the tunica intima and media during this period.

The thickness of different DA layers showed marked changes; particularly the tunica media thickness was significant probably due to the proliferation and migration of muscle layer and connective elements. The outer circular layer of tunica media showed scattered intermingled longitudinal muscle fibres (Fig.6). The tunica adventitia showed more collagen fibres, vasa nervosum and vasavasorum(Table.2)

Table 2. Thickness of DA wall $(\mathrm{N}=30)$

\begin{tabular}{|l|c|c|c|l|l|l|}
\hline \multirow{2}{*}{$\begin{array}{l}\text { Fetal Age } \\
\text { Neeks }\end{array}$ =30 } & \multicolumn{7}{|c|}{ Thickness of DA layers(mm) } \\
\cline { 2 - 7 } & Max & Min & Max & Min & Max & Min \\
\cline { 2 - 7 } & 0.027 & 0.0176 & 0.3 & 0.22 & 0.25 & 0.0381 \\
\hline $13-20(6)$ & 0.07 & 0.019 & 0.5368 & 0.251 & 1.012 & 0.12 \\
\hline $21-30(12)$ & 0.085 & 0.01 & 0.616 & 0.3598 & 0.518 & 0.03 \\
\hline $31-40(12)$ & \multicolumn{7}{|c|}{ Tunica media } \\
\hline
\end{tabular}

\section{Statistics}

The association of the length, external diameter, internal diameter, thickness of the DA with the age of the fetuses was analyzed using Karl Pearson correlation test.

The association of age with length and maximum external diameter of the DA showed high correlation co-efficient of $\mathrm{r}=0.89$ and 0.84 respectively, while the minimum external diameter was in moderate correlation co-efficient $\mathrm{r}=0.61$. The association of age with maximum and minimum internal diameter was moderate correlation co-efficient $r=0.71$ and 0.68 respectively.

The association of age with thickness of DA wall showed low correlation and the association with the tunics showed no correlation. Thus the thickness of the tunics of DA is variable with the age of the fetus.

\section{Discussion}

The DA in the early period showed the features of muscular artery with laminated elastic fibers in the tunica media similar to the description of Toda[12] and Holmes[9].The first indication of obliteration process of DA started during the early gestation period of 17 weeks and was marked by the proliferation of intimal mounds with migration of muscle and connective tissue elements by 20 weeks. Desligneres[13] and Danesino[14] 
observed the appearance of intimal cushions around 24 weeks. Gittenberger[15]reported the formation of intimal cushion in 18-21 weeks while Toda[12]reported in 15 weeks fetus.

Thus the earlier researchers have scaled the obliteration process to beginin early period of 15-24 weeks and the present study confirmed the early appearance of intimal mounds in 17 weeks. The functional closure occurred immediately after birth under the influence of bradykinin, prostaglandin level, and oxygen tension.

In group $\mathrm{C}$, the internal elastic lamina was found to be fragmented and mulitilaminar, these findings were in accordance with the findings of Muhajid[16] in the same age group.

The increase in thickness of DA wall was a stage, marking the beginning of gradual occlusion of lumen. The tunica media of DA of 13 weeks fetus showed circularly arranged muscle bundle and in the 1740weeks, the thickness of the layer increased, the muscle bundles were organized as inner longitudinal and outer circular layer. The inner layer during the formation of intimal cushion oriented perpendicularly and migrated in to the sub endothelial layer thus making the mound conspicuous. The appearance of elastic, collagen fibers and increased mucoid filled intercellular spaces were in accordance with similar findings of Muhajid[16]and Hydrina[17].

In the present study, out of 30 fetuses, 28 (93.3\%) fetuses showed closure of DA proceeding from pulmonary end to aortic end and thickening of intimal cushions played a major role in the occlusion process. These findings were in agreement with the observations made by Muhajid [16]. However, in 2 (6.66\%) specimens it was observed that the approximation of the lumen was more pronounced at the aortic end than at the pulmonary end of the DA. These findings could be due to some mechanical factor or pressure differences in two vessels or may be due to oxygen tension in the blood. Hence anatomical and physiological factor may play a role in proceeding of closure of DA from aortic side.

\section{Conclusion}

The length, the diameters and the thickness of wall of DA was directly proportional to the gestational age of the fetus. In all age groups (17-40 weeks) distinct structural changes like organization, migration and proliferation of muscle layer, appearance of elastic fibers, disrupted internal elastic lamina were observed. The first appearance of internal mounds was observed in 17 weeks and focal thickening of wall on one side and gradual formation of intercellular spaces, increase amount of connective tissue elements narrowed the lumen of DA and the multiple mound formation in 31-40 weeks marked the stage of occlusion in prenatal period. The functional closure occurred immediately after birth under the influence of bradykinin, prostaglandin level, and oxygen tension.

\section{Conflicts of interest}

All authors have none to declare.

\section{Acknowledgement}

The authors wish to thank Dr. Arunkumar Bilodi, Prof of Anatomy and Dr. S. ArunchandraSingh, Professor and HOD Anatomy, MGMC\&RI for their constant support and suggestions in this study.

\section{References}

[1]. Park M. K. Peadiatric cardiology for practioners. Part III: pathophysiology: 4th edition.2004; $96-97$.

[2]. Agren Pia, Cogolludo A.L, Kessels C G A, Pe'rez-Vizca1'no F, Mey J G R, Blanco C E, Villamor E. Ontogeny of chicken Ductus Arteriosus response to oxygen and vasoconstrictors. Am J Physiol Regul Integr Comp Physiol. 2007; 292: $485-495$.

[3]. Reese J. Death, dying, and exhaustion in the Ductus Arteriosus: prerequisites for permanent closure. Am J Physiol Regul Integr Comp Physiol.2006; 290: R357- 8

[4]. Douglas J. Schneider and John W. Moore. Patent Ductus Arteriosus. Circulation. 2006; 114:1873-82.

[5]. Charissa Richard, JuGao, Bonnie LaFleur. Patency of the preterm fetal Ductus Arteriosus is regulated by endothelial nitric oxide synthase and is independent of vasa vasorum in the mouse. Am J Physiol regul Integr Comp Physiol. 2004; 287: 652-60.

[6]. Standring S. Gray's Anatomy. An anatomical basis of clinical practice. 39th ed.2008; $1053-55$

[7]. Ronald 1 Clyman, Nancy Chorne. Patent Ductus Arteriosus- evidence for and against treatment. J. Paediatrics. 2007; Vol 150(3); 216-219.

[8]. John M Dagle, Nathan T Lepp, Margaret E Cooper. Determination of genetic predisposition to Patent Ductus Arteriosus in preterm infants. Paediatrics. 2009; 123(4): 1116-1123.

[9]. Holmes, R.L. Nerves of the rodent heart and Ductus Arteriosus. J.Anat.Lond.1957;91:606.

[10]. Sy Ho and Anderson, R.H. Anatomical closure of Ductus Arteriosus - a study in 35 specimens. J. Anat.1979;128:829-839.

[11]. Echtler K, Stark K et al. Platelets contribute to postnatal occlusion of the Ductus Arteriosus. Nature medicine; $2010 ; 16: 75-82$.

[12]. Toda T, Tsuda N. Ultrastructure of developing Human Ductus Arteriosus. J. Anat. 1980; 131(1)25-37.

[13]. Desligneres S, Larroche.J, Ductus Arteriosus-Anatomical \&Histological study of its development during second half of gestation and its closure after birth \&Histological study of a few cases of patent ductus arteriosus in infancy. Biol Neonate. 1970;16(5):278296.

[14]. Danesino VL, Reynolds SR, Rehman IH. Comparative histological structure of human ductus arteriosus according to topography, age, and degree of constriction. Anat Rec. 1955;Apr121 (4):801-829.

[15]. Gittenberger- de-Groot A C, Strengers J L, Mentink M, Poelmann RE, Patterson DF. Histologic studies on normal and persistent DuctusArteriosus in the dog. J.Am.coll.cardiol. 1985; 6(2):392-404 
[16]. Muhajid B, Galkwad P.G. A Study of histology of human ductusarteriosus before and after birth.J.Anat.soc.Ind.2000;49(1):3-5.

[17]. Hydrina D S, Swer R T, Anbalagan, Mugunthan N, Sudha Rao. Histomorphometric study of ductus arteriosus in fetuses of different age group. Nat J. BMS. 2012;3(1): 14-17.

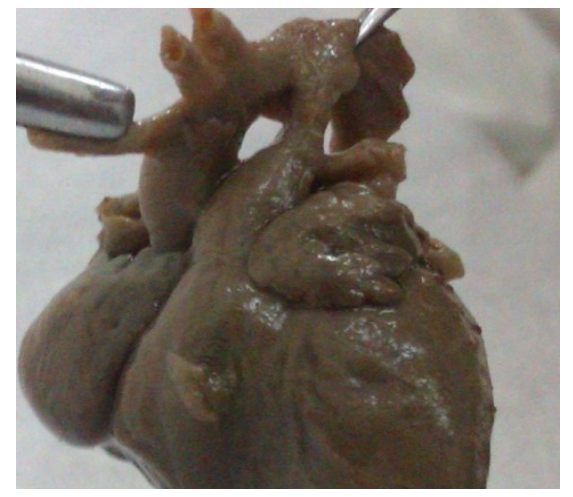

Fig.1 shows DA origin from the bifurcation of vulmonarv trunk

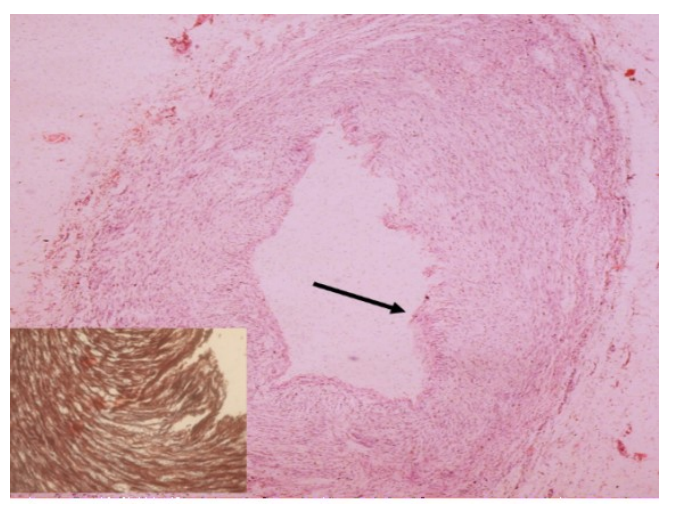

Fig.3 Photomicrograph of 17 weeks DA, arrow showing intimal cushion (10xH\&E). Insert shows oblique smooth muscle fibres in Intimal Cushions (40 x, Masson Trichrome)

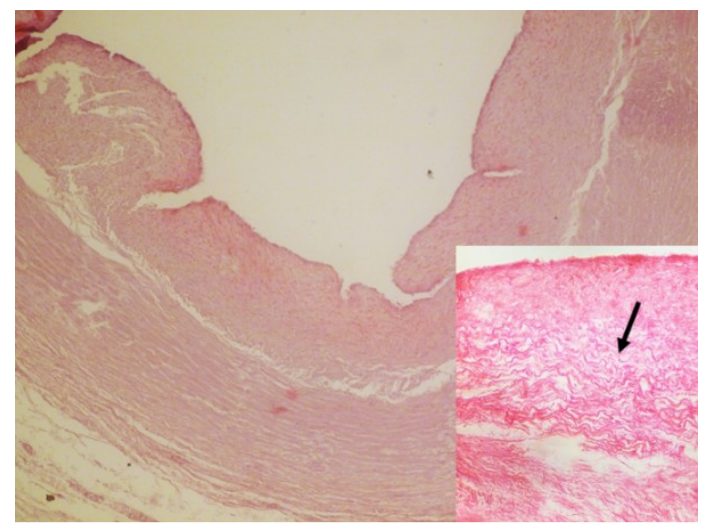

Fig. 5 shows DA of 33 weeks with intimal cushions (10xH\&E), Insert shows multilaminar internal elastic lamina $(40 \mathrm{xH} \& \mathrm{E})$

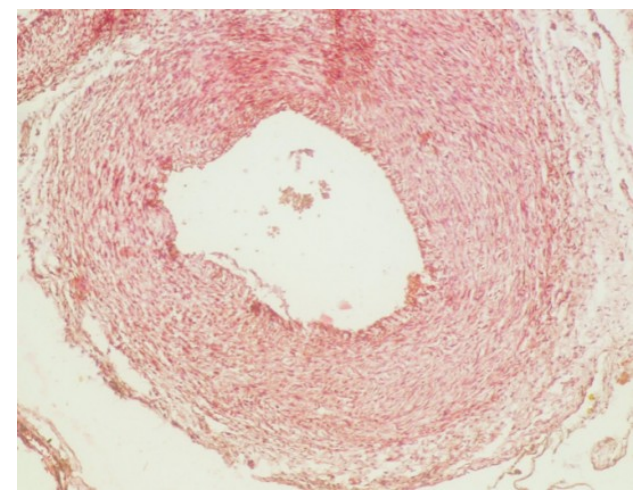

Fig.2 Photomicrograph of 13 weeks DA without any intimal cushions.(10x, H\&E)

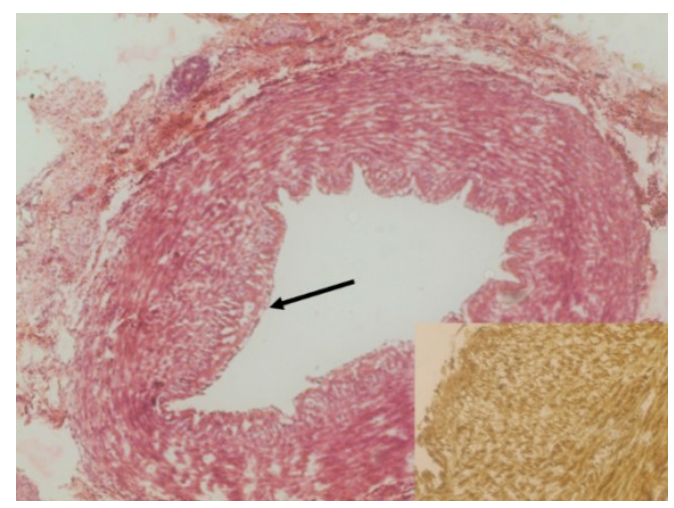

Fig.4 Photomicrograph of 23 weeks DA, Arrow shows intimal cushion (10x, H\&E), Insert shows elastic fibres in the intimal cushion (40x, Van Gieson)

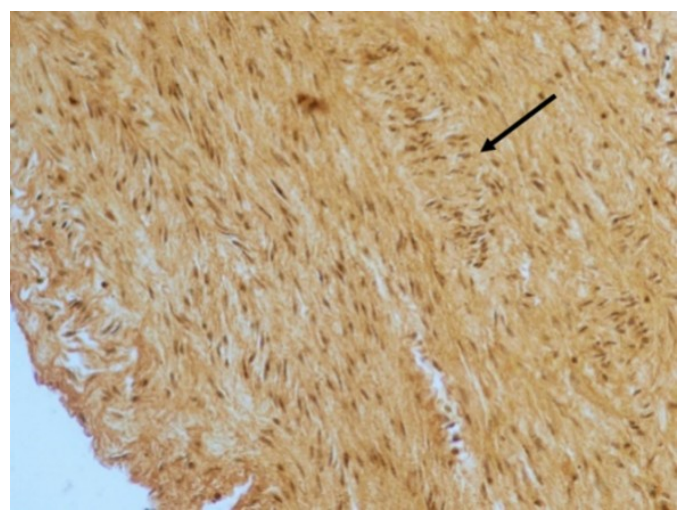

Fig.6Photomicrograph of 39 weeks DA, Arrow shows intermingled longitudinal muscle fibres in the outer circular layer (40xVan Gieson) 